\title{
A LEGITIMIDADE PSICOLÓGICA DA LINGUAGEM RELIGIOSA ${ }^{1}$
}

\author{
PSYCHOLOGICAL LEGITIMACY OF \\ THE RELIGIOUS LANGUAGE
}

Mauro Martins AMATUZZI ${ }^{2}$

\begin{abstract}
RESUMO
Este ensaio propõe-se a entender a linguagem religiosa e seu possível uso pela psicologia. Visa reconstruir sua possibilidade a partir da comparação com outras linguagens mais comumente consideradas pela psicologia. Considera, em primeiro lugar, o discurso expressivo da experiência subjetiva individual, no qual já se encontra o uso metafórico de termos pertencentes, em sua origem, à fala designativa de objetos. Em seguida, considera os discursos expressivos da experiência grupal e social, nos quais ocorre a passagem de um "eu" para um "nós". O acesso a esse "nós", como experiência subjetiva, supõe uma renúncia ao excessivo desejo de controle objetivo dos processos coletivos, e o acesso a um outro nível de racionalidade. Passa-se, em seguida, ao "nós" ecológico, cuja vivência supõe mais metáforas e renúncias, como condição de acesso. Chega-se finalmente à linguagem religiosa, na qual os símbolos e o tipo de racionalidade adquirem características novas, se bem que em continuidade às linguagens anteriores.
\end{abstract}

Palavras-chave: psicologia, religião, linguagem.

\begin{abstract}
This essay intends to understand the religious language and its possible use in Psychology. It intends to reconstruct its possibility through the comparison with other languages usually considered by Psychology. It begins considering the individual expressive speech of the subjective
\end{abstract}

\footnotetext{
(1) Este estudo foi apresentado no IX Simpósio de Pesquisa e Intercâmbio Científico da ANPEPP, em agosto de 2002, Águas de Lindóia, SP, no grupo de trabalho "Psicologia e Religião". Mantém-se aqui o tom coloquial em que foi apresentado.

(2) Prof. Dr. do Programa de Pós-Graduação em Psicologia da PUC-Campinas. Docente do Curso de Pós-Graduação em Psicologia. Endereço: Av. John Boyd Dunlop s/n - Jardim Ipaussurama CEP 13059-900 Campinas/SP.
} 


\begin{abstract}
experience, experience, in which are found the metaphonical uses the uses of terms that originally belong to the designative speech of external objects. After that, it considers the expressive speeches concerning the social and group experiences, in which can be seen the change of the "I" speech to the "we" speech. To reach this "we", as a subjective experience, means a renunciation of the excessive desire of contralling a colective process, and to access another rationality level. Then, it considers the ecological "we" as an experience, that shows more metaphors and renunciations as an access condition. Finally it reaches the religious language in which the symbols and the kind of rationality acquire new characteristics, but continuation of the former languages.
\end{abstract}

Key words: psychology, religion, language.

Ando às voltas com uma questão que neste momento se formula dentro de mim como uma necessidade: a legitimação da linguagem religiosa em face da psicologia. Que significado pode ter para a psicologia a linguagem religiosa? Mas como clarear a própria questão? Iniciando, talvez, com a busca de sua origem experiencial.

Ouvi a linguagem religiosa sendo usada por pessoas normais e respeitáveis, e fez sentido para mim. Mas a linguagem psicológica, com a qual estou mais habituado ultimamente (e com a qual me identifico como pesquisador), parece incompatível com ela. É como se fossem dois universos lingüísticos não só separados (até aí tudo bem), mas também incomunicáveis. Quando um psicólogo ouve alguém usando a linguagem religiosa, ele faz a "redução ao psicológico". E quando eu quero falar da questão religiosa, a partir de dentro de sua vivência, com algum colega psicólogo ou pesquisador, sinto a necessidade de "traduzir" o que quero dizer para outra "língua" (a psicológica, ou científica) e, então, me vem sempre a sensação de que não falei tudo, que a tradução não foi completa, que, afinal, não disse o que eu queria, na verdade, dizer.

Jogos de linguagem, diria Wittgenstein (ver, por exemplo, Coreth, 1973, p.32-33). Mas como essas "línguas" se comunicam, e qual proveito uma pode tirar de outra, principalmente em se tratando das ciências do homem? Quero dizer: quando temos como objeto de estudo o ser humano concreto, as outras linguagens (a amorosa, a artística, a religiosa...) estão querendo dizer o quê? Acreditar que elas não teriam efetivamente nada a acrescentar, que ainda não tenha sido dito pela ciência, parece um contra-senso.

Colocando a questão de outra forma: qual o valor epistêmico da linguagem religiosa? Ela efetivamente aponta para algo objetivo, para uma dimensão da experiência humana intencional? Como pode essa provável dimensão integrar uma antropologia (como ciência do homem)? Como pode o pesquisador psicólogo ouvir essa linguagem, sem restringir seu significado, isto é, sem que a redução ao psicológico fique no ar, sem se apoiar em nada?

Tomemos exemplos. Até que ponto eu posso acreditar em mim mesmo quando digo, por exemplo, que "Deus me indicou este caminho", ou que "foi por Deus que isso aconteceu em minha vida"? "Deus indicou..." significa somente que pensei isso de repente, vindo não sei de onde, mas de modo subjetivamente firme e certo como uma intuição? Ou quer dizer mais do que isso? $\mathrm{E}$ quando digo "Foi por Deus que aconteceu..." refiro-me somente a uma casualidade que me foi favorável? O que significa esse "Deus", como origem desses acontecimentos? 
Psicologicamente qual a qualidade dessa referência? Estou aqui falando de "Deus" como o centro do universo dos significados religiosos, mas poderia também falar de realidades não tão centrais: "guias espirituais", "santos", "anjos", ou mesmo "dimensão transcendente da realidade", ou "eu divino". Não passam de modos de falar?

E o exemplo mais radical é aquele em que o falante não apenas fala da dimensão religiosa, mas fala a ela, pessoalmente. Um belíssimo exemplo, mas que cito apenas parcialmente aqui:

Quero-te bem, não porque aprendi a falar-te assim, não porque o coração me sugere esta palavra, não tanto porque a fé me faz crer que és amor, tampouco somente porque morreste por mim. Quero-te bem porque entraste em minha vida mais do que o ar em meus pulmões, mais do que o sangue em minhas veias. (...) Dá que eu seja grata - ao menos um pouco - , no tempo que me resta, por este amor que derramaste sobre mim, e me obrigou a dizer-te: Quero-te bem. (Chiara Lubich, 1996)

Trata-se apenas de poesia? Ou junto com a poesia, e através dela, há outra coisa?

O que pretendo aqui é mostrar um caminho por meio do qual possamos entender o surgimento da linguagem religiosa, de modo a que algumas de suas características fiquem manifestas. Com isso, estaremos fundamentando a possibilidade de seu uso para um conhecimento do homem e da experiência humana. Chamo isso "a legitimação da linguagem religiosa".

Antes porém de entrarmos por esses caminhos, há duas questões prévias que gostaria de abordar. Uma delas refere-se à linguagem religiosa e diz respeito a seu possível caráter falacioso. Como não é uma linguagem empírica (no sentido de se referir a objetos de nosso mundo cotidiano), mas simbólica (que se refere a objetos ou relações de outra ordem, pelo caminho da metáfora ou da analogia), ela se torna passível de usos derivados. Quero dizer: é uma linguagem facilmente manipulável, tanto pelo próprio indivíduo (fazendo dela um mecanismo de defesa psicológico - o indivíduo usa da religião para não ter que enfrentar determinados problemas pessoais), como manipulável pela sociedade (grupos de poder a utilizam de forma totalmente subordinada a outros interesses, políticos, por exemplo). Resulta daí, com certeza, uma linguagem ilusória, falsa, sem valor epistêmico respeitável. Parece certo, e foi a grande contribuição de Freud e de Marx a terem denunciado. Baseando-se neles, aliás, iniciaram-se as leituras redutivas do discurso religioso. Pois bem, estamos aqui partindo do pressuposto de que isso é possível, sem dúvida, mas de que não podemos cientificamente restringir todo valor possível da linguagem religiosa a esses tipos de usos derivados. Não podemos excluir a priori a possibilidade de haver um uso epistêmico real dessa linguagem, e isto quer dizer um uso efetivamente revelador de um âmbito real da experiência humana. O mesmo poderíamos dizer, aliás, da linguagem artística ou da amorosa.

Antes de passarmos para nosso segundo ponto prévio, gostaria de abrir um parêntese aqui, para comentar um belo trecho de fala do escritor e poeta gaúcho Armindo Trevisan, numa entrevista concedida a José Antônio Faro (Faro, 2002, p.21 e 22), no qual ele articula a experiência artística com a religiosa, e usa em parte a linguagem religiosa. Diz ele:

Eu creio que toda arte autêntica nos aproxima de Deus, porque, como diria Dante, "a arte é um reflexo de Deus". Até pela atitude desinteressada do artista. Na hora que o poeta faz um belo poema a seu pai, ou a sua amada, ele está louvando coisas que estão além do dinheiro, além da cobiça, além da raiva, da inveja, do racismo e do ódio. Há nesse caráter desinteressado da beleza, pela sua busca de uma situação ideal, uma 
espécie de prelúdio da fé, porque a fé exige que o homem abandone seus pequenos "brinquedos", penduricalhose quinquilharias e passe a aceitar os dons de Deus que são a vida, a inteligência, o amor, e, principalmente, a sobrevida, a sobreinteligência e o sobreamor. Realmente a arte tem uma função muito importante como pedagogia da fé. (Faro, 2002, p.21-22)

Ele está falando aqui das relações possíveis da arte com a fé religiosa e, de alguma forma, dá conta da experiência religiosa enquanto uma experiência humana original. Esse dar conta consiste em ver no caráter desinteressado da poesia, uma "espécie de prelúdio" de uma outra experiência que tem nessa gratuidade e nesse abandono, também a sua essência. Só que nessa outra experiência ocorre uma aceitação da vida, da inteligência e do amor, como dons e, principalmente, uma aceitação de uma "sobrevida", de uma "sobreinteligência" e de um "sobreamor" também como "sobredons", diríamos. A experiência humana da arte é vista como experiência que contém potencialmente uma outra experiência que, no entanto, transcende a primeira, como uma novidade. Fala-se de uma vida de outra ordem, de uma inteligência de outra ordem, e de um amor de outra ordem, mas realmente experienciados. E dessa outra ordem encontramos um "prelúdio" na experiência artística, por causa do desinteresse ou gratuidade de seu objeto.

O que ocorre aqui? Como a arte pode ser um prelúdio da fé? O artista experimenta realmente a gratuidade ou o caráter não interesseiro daquilo que ele faz (ou aprecia). Mas quem já experimentou a ordem de gratuidade da fé religiosa (do "sobreamor", da "sobreinteligência", da "sobrevida") é capaz de ver mais claramente na experiência artística o seu alcance de prelúdio. Sem essa segunda experiência, o máximo que poderíamos dizer é que esse caráter de prelúdio é "pressentido" vagamente, apenas. É como no tradicional exemplo: vejo que alguém vem vindo, mas não vejo quem é. Só o saberei quando ele chegar mais perto (se eu permitir que chegue). Em outras palavras: existe algo na experiência artística que se mostra com maior clareza à luz de outra experiência. Mas já está ali, de algum modo. Seu caráter de "prelúdio" pode ser pressentido.

Fechemos o parêntese e passemos ao segundo ponto prévio que queria abordar. Se o primeiro dizia respeito à linguagem religiosa, este diz respeito à linguagem científica. Atualmente com a emergência das pesquisas qualitativas ou compreensivas no âmbito das ciências humanas (ver González Rey, 2002, por exemplo), não podemos mais dizer que toda linguagem científica é do tipo explicativo. O que significa explicar? Significa descobrir a causa própria de algum evento ou a função na qual ele ocorre. No âmbito da psicologia, enquanto estudo da subjetividade, o mais importante não parece ser a atribuição de causalidade (ou de funcionalidade), mas sim a compreensão. A "explicação funcional" cede lugar ao "dar conta", à apreensão do sentido. $E$ isso tem relação com um novo tipo de prática psicoterápica (na verdade, antigo): aquele que se baseia no fato de que a própria pessoa encontrará mais facilmente seus caminhos de desenvolvimento, se for plenamente compreendida, isto é, ajudada a se aproximar de seus significados, num ambiente inter-humano honestamente dialógico (a esse propósito, ver o interessante diálogo de Buber com Rogers, em Buber 1965). E isso passou para a pesquisa. A linguagem compreensiva (e não a explicativa) é a que está presente nas pesquisas de tipo fenomenológico e hermenêutico na psicologia. É a linguagem do "dar conta", isto é, do tornar presente, com sentido, no mundo de significados. Isso é importante em nosso caso: o que pretendemos aqui não é explicar a linguagem religiosa, mas dar conta, reconstruir sua possibilidade. Qualquer linguagem é, primeiramente, um dar conta. Só derivada- 
mente, e de forma subordinada, ela serve a outros propósitos (cf Merleau-Ponty, 1973, 1996).

Podemos agora retomar nosso caminho visando "dar conta" dos diferentes níveis de realidade experienciáveis pela pessoa, com suas respectivas linguagens. Proponho a idéia de "processo" como guia, pois a experiência subjetiva é um processo. Que tipos ou níveis de processo podemos considerar? (Retomo aqui um percurso que comecei a explorar em Amatuzzi, 2001, p.117-131).

Consideremos o nível individual, primeiramente, mais próximo à psicologia. Gostaria de partir do comentário que ouvi de um psicoterapeuta: "Meu paciente já está em tratamento comigo há 3 meses, mas ainda não entrou em processo". O que pode significar "ainda não entrou em processo", se o paciente já está em tratamento há 3 meses? Parece claro que a palavra processo tem aí um significado especial. Não designa simplesmente o estar em tratamento, tendo entrevistas toda semana, com horários e honorários contratados. Se tudo já começou, que processo é esse que não começou ainda? Sabemos, no entanto, que os encontros terapêuticos podem ter começado sem que se tenha iniciado ainda uma mobilização interior que merecesse ser chamada de processo psicológico num sentido próprio. Mobilização interior, eis aí.

Podemos, então, dizer que existem dois sentidos da palavra "processo" neste contexto. Um se refere à mobilização "exterior" dos encontros terapêuticos já começados. Digamos que isso pode ter iniciado sem que a troca de significados tivesse ainda atingido um nível de "mobilização interior", mais profunda. Chamemos a isso de "processo relacional", uma coisa acontecendo em seguida à outra, no contexto de encontros que se repetem sistematicamente. Outra coisa é o "processo pessoal," propriamente dito. É quando a pessoa começa a se questionar, não apenas no que diz respeito aos seus comportamentos, mas no que se refere às suas estruturas de orientação, àquilo que está por trás e faz a lógica ou a coerência de seu modo de viver. $E$ mais: não apenas quando começa a se questionar intelectualmente, mas quando esse duvidar é vivido existencialmente, é sentido, de modo tal que a pessoa não possa mais ficar protegida de possíveis mudanças (e da vertigem que acompanha esse sentimento). Esse é o verdadeiro processo que pode demorar a começar mesmo que os encontros terapêuticos já se tenham iniciado há bastante tempo. Uma pessoa pode ter uma vida agitada, cheia de coisas diferentes, mas no fundo estar parada, sempre dentro dos mesmos padrões.

Podemos nos perguntar quando ocorre o processo pessoal, no sentido próprio. E a resposta é aparentemente simples: quando a pessoa entra em si mesma, e vai às raízes de seu agir. Em outras palavras: quando ela faz contato com seu centro, o centro da pessoa (como diz Buber, 1982), ou o "coração". Gosto dessa expressão "coração", porque ela é tradicional, anterior à própria psicologia, e todos a entendem. Quando alguém diz: "o que eu faço?" e lhe perguntam "o que seu coração está dizendo?", a primeira pessoa entende o que isso significa. Sabemos o que é o coração do ser humano. Mas aqui é preciso tomar cuidado: não é simplesmente o sentimento. Melhor é dizer: é o lugar de onde nascem os sentimentos. Porque é também o lugar de onde nascem os pensamentos, e as decisões (ou intenções efetivas). Ou seja, é aquele lugar dentro de nós mesmos onde pensamento, sentimento e intenção não se diferenciaram ainda. É a fonte. Entramos em processo pessoal quando contatamos a fonte. Quando abrimos a porta do coração. Mas a psicologia tem esquecido de falar em coração.

Existe uma linguagem própria e adequada para descrever esse processo interior, e que é diferente da linguagem usada para se descrever o processo exterior. É a linguagem do sentimento, do vivido, das intenções, das inspirações, dos desígnios, e que se apresenta 
freqüentemente de modo metafórico. Basta vermos no parágrafo precedente as expressões: "entrar em si mesmo", "raízes do agir", "coração", "lugar de onde nascem...", "interior", "fonte". Todas, expressões metafóricas. É uma linguagem que nasce de uma relação subjetivamente considerada, tomando os termos concretos da linguagem objetiva para fazê-los significar realidades de outra ordem; enquanto a outra linguagem, mais adequada ao processo externo, surge de uma relação objetivamente considerada, e usa os termos concretos na mesma ordem de significados. $\mathrm{O}$ discurso (objetivo) que visa dizer o processo exterior, reconstrói fatos; o discurso (fenomenológico) que visa dizer o processo interior, reconstrói significados. São dois tipos de linguagem, ambos necessários se quisermos dar conta de nossa experiência.

Agora: existem dois tipos de fenomenologia. Uma que diz o que se apresenta na consciência, e outra que diz o que se apresenta à consciência. A diferença é que na segunda mantém-se a intencionalidade, a referência. Só ela, a meu ver, é verdadeiramente fenomenologia. O discurso que lida com os significados pode estar na boca do pesquisador que olha a experiência como que de fora, como também pode estar na boca do sujeito que fala a partir de dentro de sua experiência, vivenciando sua intencionalidade própria (sua referência). O discurso do pesquisador (assim como o do psicoterapeuta) será adequado quando recebe essa intencionalidade e dá conta dela (a reconstrói).

Passemos agora do âmbito individual para o dos processos grupais. Podemos, aqui também, falar de dois significados para "processo", um superficial e outro profundo. O processo grupal, no sentido externo e superficial do termo, corresponde a tudo o que acontece num grupo como conseqüência dos fatos externos que se abatem sobre ele. Uma turma de faculdade, no último ano do curso, já não é mais a mesma que era no primeiro ano. Muita coisa aconteceu e influenciou a configu- ração do grupo. As pessoas individualmente cresceram, formaram-se subgrupos, amizades e antipatias foram se cristalizando, etc. O grupo passou por todo um "processo" (que pode ser descrito em linguagem objetiva, relacionando cada coisa com suas prováveis causas ou estabelecendo relações funcionais). Bem diferente deste será, contudo, o processo de um grupo "se assumir como grupo", enfrentando em conjunto as influências externas e chegando a ter um certo controle sobre elas (e desenvolvendo-se a partir daí). Se a comunicação interna entre os membros for aberta e honesta, e houver a disposição da cooperação em vista de um objetivo comum, transforma-se pouco a pouco o agrupamento casual em um verdadeiro grupo. Ocorre um desenvolvimento do grupo como grupo, de forma integrada com o desenvolvimento de seus membros enquanto pessoas. Este seria um processo num sentido mais profundo, que se compara com o outro, da mesma forma como o processo individual pessoal (interno) se compara com o relacional (externo), no nível individual. Ou seja, existe um processo grupal, propriamente dito, que é diferente das mudanças externas ocorridas no grupo. Ele pode ser experienciado pelas pessoas em seu nível próprio.

Assim como no nível individual, aqui também, a condição para esse processo grupal é a comunicação interna (entre os membros do grupo) e o contato com o centro. No âmbito do grupo, esse centro se mostra como "sabedoria grupal" (uma vez que o processo se instaura). É uma sabedoria que atua independentemente de ter sido verbalizada diretamente (isso foi descrito, por exemplo, por Wood, em Rogers, Wood, O'Hara \& Fonseca, 1983). E uma outra característica do contato com este centro é a renúncia necessária a um excessivo desejo de controle racional. Há aí algo que ultrapassa o indivíduo (e sua razão particular), e o acesso a isso fica bloqueado se o indivíduo se posiciona de forma fechada, isolada, rígida. Todos nós conhecemos esse fenômeno: se não há uma 
confiança nos próprios processos grupais, a grupalidade verdadeira não chega a se instaurar.

A linguagem expressiva do processo interno do grupo (tal como vivido e testemunhado pelas pessoas) deve operar uma modulação importante em relação à do processo individual: passamos do plano do "eu" para o do "nós". O que "eu" quero é uma coisa. O que "nós" queremos é outra. E não apenas porque queremos coisas diferentes, mas porque a própria vivência subjetiva do "nós queremos" é diferente da vivência subjetiva do "eu quero". E, no entanto, o "nós queremos" é uma experiência real à qual podemos ter acesso (mas também podemos perder esse acesso, se tivermos uma atitude excessivamente egocentrada ou estivermos pretendendo um total controle racional). O referencial empírico no "nós queremos" torna-se mais difuso e vago. Mas é possível falarmos individualmente tendo o "nós" como sujeito. Não há aí uma traição lingüística. Isso corresponde a uma experiência real, só que de outra ordem em relação à experiência do "eu". E é possível também agirmos a partir desse "nós". E esta ação não será simplesmente a soma de ações individuais. Ela pressupõe coesão, comuni-cação aberta e honesta, e disponibilidade para sabedoria do coletivo (com a correspondente dose de renúncia). A linguagem do "nós" transcende a linguagem do "eu", e não pode pronunciá-la com verdade quem não estiver vivenciando um processo grupal propriamente dito. Ela corresponde a um outro âmbito da experiência, real e diferentemente empírico (se podemos nos expressar assim). Mas essa diferença não é absoluta: ela é inclusiva. A experiência do nós só é verdadeira quando integra a do eu, e a potencializa.

O que tudo isso tem a ver com a linguagem religiosa? Estamos construindo sua possibilidade, e eu solicito sua paciência que logo chegaremos lá. Mas quando isso acontecer, se o leitor me tiver acompanhado, ela já estará clara, assim espero. Assim é o discurso fenomenológico.

Se dermos um passo além e considerarmos o social, veremos coisas análogas. Existe um processo social no sentido superficial do termo. É o que ocorre numa sociedade quando ela é vítima dos acontecimentos externos que se abatem sobre ela. Mas é possível se pensar num processo social num sentido mais profundo. É quando, hipoteticamente, um povo (uma nação, uma comunidade de origem e de destino) "se assume como comunidade", deixando assim de ser apenas vítima dos acontecimentos externos, mas podendo ter sobre eles algum poder de controle, enquanto unidade coesa. A complexidade aumenta muito aqui. E não é apenas uma questão de quantidade. A intimidade, por exemplo, possível ao nível do grupo, já não é mais possível aqui. Contudo, isso não significa que não haja mais comunicação. Pelo contrário, ela deve continuar existindo. Que se pense, por exemplo, em assembléias deliberativas comunitárias, em orçamento participativo, em organizações populares ou institucionais, etc. Existe sempre a possibilidade de manipulação política nesse nível, mas enquanto estiver acontecendo isso com êxito por parte dos manipuladores, não haverá ainda processo social no sentido próprio de uma comunidade que se assume. Quando há esse processo, a política adquire outro significado: o de atenção ao que é comum, de todos. Em suma, mesmo que não possamos identificar muito facilmente exemplos históricos duradouros de um verdadeiro processo social, ele é pensável como possível. O verdadeiro processo social é tão diferente do processo de mudança externa em uma sociedade, que, a meu ver, deveríamos ter um outro nome para ele. Acho que poderíamos denominá-lo "processo comunitário". Ele é também um processo inclusivo dos anteriores, isto é, nele as pessoas são plenamente pessoas e, ao mesmo tempo, estão envolvidas com o seu destino enquanto 
comunidade. A comunicação continua sempre importante e, embora não seja aqui "íntima", deve ser aberta e honesta (o que pressupõe muita coragem, diga-se de passagem). $O$ centro (ou "espírito do povo"), aqui, vai também se manifestando, mas isso pressupõe uma renúncia ainda maior ao excessivo controle racional, o que equivale a um desenvolvimento muito grande da capacidade de ouvir o que se manifesta de mais verdadeiro no coletivo. No plano da linguagem passamos de um "nós grupal" a um "nós comunidade" (por exemplo, um "nós" latino-americano, ou mesmo um "nós" humanidade). Mas ninguém pode falar esse "nós" se não estiver vivenciando um verdadeiro processo comunitário, no interior de uma sintonia com os participantes daquela condição comum. Há, portanto, uma mudança de linguagem aqui também, e que pressupõe o acesso vivido a um nível experiencial de outra ordem, coletivo, político. Falar desse nós sem essa experiência comunitária, seria uma farsa ou uma impostura. Mas essa nova linguagem, quando a pessoa está envolvida no processo, expressa uma dimensão real de sua experiência. Nova, inclusiva, potencializadora das anteriores. É no político (assim entendido), ou na comunidade efetivamente vivenciada, que me torno mais plenamente eu mesmo.

Existe um outro âmbito para o qual estamos nos abrindo mais, recentemente. É o âmbito dos processos ecológicos, que enquanto envolve uma nova consciência, talvez não se encontre ainda plenamente elaborado. Andamos aprendendo com os índios... Vale a pena considerarmos suas características, pois elas vão nos trazer elementos novos para a compreensão das linguagens. Aqui também podemos constatar dois significados de processo. Uma coisa é "preservar nossas riquezas que estão sendo destruídas". Outra, bem diferente, é "preservar o meio ambiente do qual fazemos parte". O meio ambiente não é nosso. Nós é que somos do meio ambiente, e com ele formamos um novo "nós" que vai além do social comunitário. No primeiro caso, o homem se vê como centro de referência, dominando a natureza, podendo usufruir dela a seu bel-prazer. Então reage quando esse prazer e essa riqueza the são tirados. No segundo caso, ele não se coloca no centro, sabe-se um participante. É uma outra maneira totalmente diferente de ver as coisas. No primeiro caso, o processo ecológico está fora do homem (e ele o preserva como a uma fonte de bens de consumo). No segundo caso, o processo inclui o homem e é a integração consciente para ele que se configura como um processo interior, uma mudança de atitude. Quem não efetuou essa mudança, ou não vivencia essa consciência, não pode entender uma frase como esta: "os remédios necessários para curar nossas doenças podem ser encontrados em nossa vizinhança geográfica". Ou esta: "devemos nos aproximar dessa árvore centenária com respeito porque ela guarda a memória do que aconteceu em sua sombra". À luz dos outros âmbitos de consciência, são frases místicas ou poéticas, em todo caso sem apoio empírico. Mas para quem tem a vivência do todo sistêmico do qual fazemos parte, e no qual nos constituímos, ou para quem ousou esse salto epistemológico, essas frases podem trazer um sentido novo e, por mais inusitado que possa parecer, real.

O "nós" a que, nesse nível, nos referimos é maior que o "nós" social, pois inclui animais, árvores, nascentes, rios, ventos, terra, etc. $\mathrm{O}$ sujeito do processo ambiental não é mais o homem, embora ele possa ter aí o papel fundamental de consciência. A renúncia necessária para se ter acesso a esse nível experiencial é maior: é a renúncia a um determinado conceito fechado de eu. E o caminho inclui a mobilização de mais do que somente a razão instrumental. Passa, por exemplo, por aquelas faculdades que nos fazem fechar uma torneira, não apenas para não desperdiçar água, mas por respeito. O centro de consistência que emerge quando se tem esse acesso não é mais uma "alma do povo", mas talvez uma "alma do lugar" e, com certeza, 
precisa ser mais estudado. Em todo caso remete a símbolos antigos: os espíritos da floresta, ou os deuses da chuva. E esse nível experiencial é também inclusivo dos anteriores: o que acontecer à Terra, acontecerá aos filhos da Terra, diz a velha sabedoria indígena. É integrando-nos ao meio ambiente que nos encontraremos como pessoas.

No entanto, não somos formigas: o ser humano não se esgota no ecológico (assim como não no social). Isso também faz parte de nossa experiência. O ser humano é aquele que pode por a cabeça para fora dos sistemas e olhar para eles. E é só então que eles se tornam belos. Estamos ainda aprendendo a consciência ecológica e a correspondente linguagem expressiva. Mas podemos dizer que existe um outro âmbito maior ainda. É o âmbito do todo, vivenciado pelo ser humano na experiência do horizonte. Podemos pensar nisso, e não há como reduzir essa dimensão. É tão antiga como a humanidade.

Existe o processo do todo. O universo é um processo, e seu centro está em toda parte. Muitos grandes homens suspeitaram de uma intenção que atravessa o processo universal, e isso ecoa dentro de cada um de nós, independentemente da posição que acabemos por assumir. Isso tem a ver com os graus mais avançados de religiosidade ou de espiritualidade alcançados na história da humanidade. O sujeito desse processo universal, uma vez mais, não é o ser humano. O que ele pode fazer é inserir-se nele, ofertando-Ihe também sua consciência (sua inteligência, sua vontade, seu amor, seu respeito). E aqui há, de novo, a necessidade de uma renúncia a um excessivo controle racional, para que esse centro possa se manifestar no campo experiencial. O salto qualitativo é maior, a transcendência em relação aos âmbitos anteriores é maior. Mas é um salto necessário, se quisermos dar conta da totalidade da experiência humana.

É importante notar que a religião foi durante muito tempo a portadora cultural dessa dimensão da experiência (Amatuzzi, 1999). Mas ela pode também se enrijecer e desvirtuar essa sua vocação. A história de muitos reformadores está aí para atestar esse desvirtuamento, por um lado, e o vigor original da experiência, por outro. Esses dois pólos são muito fortes. Os reformadores acabam assimilados pelo sistema (e a religião se torna algo reacionário, como diz Fromm (1974)), mas também sua seiva original não morre. Podemos pensar num conceito mais vivo de religião, mais abrangente, não necessariamente estruturado em torno de conceitos. Seja lá como for, a consciência humana tem acesso a um processo universal. O sujeito desse processo, como dissemos, não é o homem, mas ele pode inserir-se nele também, respeitosamente. Esse passo supõe deixar para trás uma individualidade fechada com sua racionalidade correspondente. Supõe um entregar-se (e isso é muito mais do que um asséptico ato de conhecimento). Nessa ponta vertiginosa da experiência humana, pensamento, sentimento e decisão de novo se confundem ou são transcendidos. A linguagem vira um balbucio. As metáforas se multiplicam. Os conceitos se relativizam, inclusive o conceito de Deus (pois ele podia estar sendo entendido como uma coisa dentre as outras que existem).

Mas é preciso dizer também que esse âmbito experiencial é inclusivo. Ele supõe a transcendência dos anteriores, mas não os elimina. Pelo contrário, integra-os. Carrega as experiências anteriores para um contexto no qual elas adquirem seu sentido último. E se pode falar, com Trevisan, de uma "sobreinteligência", de um "sobreamor" e de uma "sobrevida", porque o âmbito de significados é aí bem diferente.

Por mais perdida que esteja a linguagem humana neste nível experiencial, ela corresponde a um esforço de "dar conta", na medida do possível, do que aí realmente se passa. E mais, corresponde a um esforço de 
expressão do posicionamento dialógico que aí ocorre. Quando isso é feito a partir do interior da própria experiência, estamos diante da linguagem religiosa direta, e o objeto da experiência ao qual ela remete é o "algo mais" de que falávamos no começo, um outro nível de significados necessários para se dar conta do real.

Convém salientar que o processo nesse nível não tem como sujeito o homem, mas o mundo, no sentido mais amplo do termo. A participação consciente do homem nele é o processo espiritual ou religioso (pelo qual o homem se religa ao todo, ou ao seu centro). A expressão "processo religioso", contudo, pode ter também um duplo sentido: um mais superficial e outro mais profundo. No seu sentido superficial e externo, ele corresponde à seqüência de eventos objetivos nesse campo: mudanças de denominação religiosa, mudanças de vida conseqüentes a obediência a preceitos, aquisição ou alteração de crenças, etc. Tudo que pode ser descrito dentro de uma abordagem explicativa, objetivante. Mas aqui o "processo religioso" pode se abater sobre a pessoa opressivamente. Somos então vítimas da religião. Mas, num sentido mais profundo, o ser humano "se assume nessa religação" e, mesmo recebendo com renúncia e submissão o que the vem, ele reafirma sua liberdade num nível experimentado como mais real. Existe um "nós" aqui também. Mas o seu referencial empírico, aos olhos dos âmbitos anteriores, é tão mais difuso, que muitos preferem denominálo simplesmente místico, quase como sinônimo de inexistente (o que não é bem verdade). É que a religação é experienciada somente a partir de seu pólo subjetivo, permanecendo o objetivo (o centro do universo religioso) oculto em si mesmo. A linguagem religiosa, por isso, é uma linguagem eminentemente simbólica. $\mathrm{O}$ referencial empírico passa a ser a vivência subjetiva, mas esta tem uma intencionalidade própria, vivenciada: o centro, o mistério que, em si mesmo, é oculto. O acesso a ele é indireto, pressupõe a renúncia máxima à racionalidade objetivante, e um ativar do centro da pessoa, em sua raiz. Mas dá origem à sobreinteligência, ao sobreamor, e à sobrevida que são testemunhados. Há um salto aqui, e não somente de uma parte da pessoa, mas da pessoa inteira.

É sem dúvida muito difícil falar disso sem tropeçar. E isso explica, em parte, porque o discurso religioso não cabe no discurso da ciência. Não porque não expresse uma dimensão real da experiência humana, mas porque o referencial empírico da ciência é limitado. Reconhecemos visualmente o sol, mas não podemos olhar para ele diretamente sem ficarmos cegos. A linguagem religiosa tenta essa proeza quase impossível: não só falar do mistério, mas também falar ao mistério. E depois ouvi-lo. É isso que ela é quando corresponde a um processo pessoalmente vivenciado, processo no sentido de mobilização interior, e não apenas no sentido de algo que, de fora, institucionalmente, se abate sobre as pessoas.

Mas como esse âmbito de experiência é também inclusivo dos anteriores, ele assume numa outra ordem, o âmbito ecológico (por exemplo, a experiência de um "corpo místico"), o âmbito social (por exemplo, no caráter comunitário e solidário da experiência religiosa) e até mesmo o âmbito do processo grupal e individual (no apreço ao grupo de base, e na potencialização da "vida interior" pessoal com todas as suas dimensões psicológicas orquestradas no novo contexto). Nesse sentido, existe uma linguagem religiosa que se faz até psicológica. Em todo caso, parece certo que a psicologia não pode desconsiderar essa expressão de uma experiência humana possível. E pode se aproximar compreensivamente dela.

Terminamos aqui nosso percurso. Chegamos à linguagem religiosa, reconhecendo nela aspectos que já havíamos encontrado antes nas linguagens de outros âmbitos da experiência humana de estar em processo, só que aqui essas características 
estão no seu limite. Era o que eu gostaria de propor. Ficaria muito feliz de poder continuar pensando nisso, agora junto com os leitores ou ouvintes, e me abro aos seus comentários.

\section{REFERÊNCIAS BIBLIOGRÁFICAS}

AMATUZZI, Mauro (1999). Religião e sentido de vida: um estudo teórico. Temas em Psicologia da SBP, 7(2): 183-190.

AMATUZZI, Mauro (2001). Por uma psicologia humana. Campinas: Alínea.

BUBER, Martin (1982). Do diálogo e do dialógico. São Paulo: Perspectiva.

BUBER, Martin (1965). The knowledge of man. London: George Allen \& Unwin.

BUBER, Martin \& Carl ROGERS (1965). Dialogue between Martin Buber and Carl Rogers. In BUBER, Martin. The knowledge of man. London: George Allen \& Unwin. Pgs. 166-184.

CORETH, Emerich (1973). Questões fundamentais de hermenêutica. São Paulo: EPU, EDUSP.
FARO, José Antônio (2002). Uma poesia feita de fé e esperança (entrevista com Armindo Trevisan). Cidade Nova, 44(8):21-23.

FROMM, Erich (1974). Análise do homem. Rio de Janeiro: Zahar.

GONZÁLEZ REY, Fernando Luis (2002). Pesquisa qualitativa em psicologia. São Paulo: Pioneira Thomson Learning.

LUBICH, Chiara (1996). Desenhos de luz, meditações e imagens. São Paulo: Cidade Nova.

MERLEAU-PONTY, Maurice (1973). Ciências do homem e fenomenologia. São Paulo: Saraiva.

MERLEAU-PONTY, Maurice (1996). Fenomenologia da percepção. São Paulo: Martins Fontes.

ROGERS, C.; WOOD, J; O'HARA, M.; \& FONSECA, A. (1983). Em busca de vida. São Paulo: Summus.

Recebido para publicação em 05 de setembro de 2002 e aceito em 03 de dezembro de 2002. 